\title{
MEGA SPORTING EVENT LEGACIES: A MULTIFACETED CONCEPT
}

\author{
JEAN-LOUP CHAPPELET ${ }^{1}$ \\ Swiss Graduate School of Public Administration (IDHEAP) \\ University of Lausanne \\ Switzerland
}

Fecha recepción: julio de 2012

Fecha aceptación: octubre de 2012

\begin{abstract}
The legacy of mega sporting events can be perceived in several ways. It can be seen as positive or negative, tangible or intangible, territorial or personal, intentional or unintentional, global or local, short- or long-term, sport- or non sport-related, and can also be seen from the various event stakeholders' perspectives. In fact, it is much more appropriate to talk about legacies in the plural than simply legacy. This paper gives a broad overview of an often used but rarely defined concept, using examples from the legacies of the Olympic and Commonwealth Games, arguably two of the most important mega sporting events. It concludes that legacy essentially is a dream to be pursued rather than a certainty to be achieved.
\end{abstract}

KEY WORDS: Commonwealth Games, impact, legacy, Olympic Games,

\section{RÉSUMÉ}

L'héritage d'un grand événement sportif peut être perçu de multiples façons. On peut le voir comme positif ou négatif, tangible ou intangible, territorial ou personnel, intentionnel ou non, global ou local, à court ou long terme, lié au sport ou non, et aussi selon la perspective de ses différentes parties prenantes. En fait, il est bien plus approprié d'employer le terme d'héritages au pluriel qu'au singulier. Cet article donne une vue d'ensemble d'un concept souvent utilisé mais rarement défini - celui d'héritage (legacy en anglais) - en utilisant des exemples provenant des Jeux olympiques et des Jeux du Commonwealth, deux des plus grands événements sportifs multisports régulièrement organisés. II conclue que l'héritage est pour l'essentiel un rêve à poursuivre plutôt qu'une certitude à atteindre pour ce qui concerne les grands événements sportifs.

MOTS CLÉS : héritage, impact, Jeux du Commonwealth, Jeux olympiques.

JEL: L83.

\footnotetext{
${ }^{1}$ An earlier version of this paper was presented at "The Games and the Commonwealth" Conference, Delhi, India, March 2010. 
Chappelet, Jean-Loup. Mega sporting event legacies: a multifaceted concept.

\section{INTRODUCTION}

The concept of the legacy of mega sporting events appeared within sport management during the 1990s, when questions about the costs and benefits of organising them were first raised from not only the financial and economic point of views but also with respect to social and environmental aspects. This is when the word "legacy" started to appear in the mega sporting event organisers' and owners' discourse and literature.

Here are a few examples and quotes where the "L word" is emphasised. In 1991, the Organising Committee for the 1996 Centennial Olympic Games in Atlanta included the following goal within its mission statement: "To leave a positive physical and spiritual legacy and an indelible mark on Olympic history by staging the most memorable Olympic Games ever."(ACOG 1997). Three years before the 2002 Commonwealth Games in Manchester, a "Commonwealth Games Opportunities and Legacy Partnership Board" was established by the UK city to handle the post-games phase. In 1997, the Candidature Committee for the 2004 Olympic Games in Athens entitled a brochure presenting its project: "A legacy for Olympism" (ABC 1997). At the opening ceremony of the 1998 Winter Games in Nagano, the President of the International Olympic Committee (IOC) mentioned: "the cultural legacy of our predecessors" (NAOOC 1999). The IOC Evaluation Commission that was created to assess candidatures for the 2008 Games stated in its 2001 report: "It is the Commission's belief that a Beijing Games would leave a unique legacy to China and to sport." (IOC 2001: 95). In 2003 the IOC modified its Charter to include a fourteenth mission: "To promote a positive legacy from the Olympic Games to the host cities and host countries" (rule 2.14). The Organising Committee of the Commonwealth Games 2010 Delhi stated on its website as one of its seven missions: "Leave behind a lasting legacy". London 2012 is so far the mega sporting event whose promoters have probably most used the " $L$ word" at both bidding and organising phases. This rhetoric has been adopted by the British Government which identified three years after the awarding of the event five main Olympic commitments in a Legacy Action Plan (LAP):

1) To make the UK a world-class sporting nation, in terms of elite success, mass participation and school sport.

2) To transform the heart of East London.

3) To inspire a new generation of young people to take part in local volunteering, cultural and physical activity.

4) To make the Olympic Park a blueprint for sustainable living.

5) To demonstrate that the UK is a creative, inclusive and welcoming place to live in, to visit and for business." (DCMS 2008: 6-7)

As we can see from these few examples, the concept of legacy is vast and above all somewhat unclear. The purpose of this article is to clarify it to better understand the rationale for mega sporting events. In doing so, it is useful to propose a working definition of the concept: The legacy of a mega sporting event is all that remains and may be considered as consequences of the event in its environment. This definition will permit us to explore, step by step, the various facets of the concept, using each of the segments of this definition shown in italics as section headings, before concluding the paper by outlining the way in which a city can maintain a lasting 
Chappelet, Jean-Loup. Mega sporting event legacies: a multifaceted concept.

legacy from the events it organises.

\section{ALL THAT REMAINS}

Many authors have attempted to categorise "all that remains", i.e. the various types of legacy. Cashman (2003) identifies six: Economic; Physical infrastructure; Education; Public life, Politics and culture; Sport; Symbols, memory and history. Chappelet (2003) proposes five others: Tourism and Economy; Infrastructure; Sport facilities; Urban and natural environment; Socio-cultural. Hiller (2003) specifies four Olympic "outcomes": Built environment; Economic development; Memories; Communities. Gratton and Preuss (2008) identify six "event structures": Infrastructure; Knowledge, skill-development and education; Image; Emotions; Networks; Culture. The IOC (2009) outlines five Games legacies: Sporting; Social, cultural and political; Environmental; Economic; Urban.

Continuing to propose typologies of legacy would seem futile, since it is possible to segment all that remains after a mega (sporting) event almost ad infinitum. It seems important, however, to distinguish three major dimensions of legacy with regard to their material, territorial and sporting nature.

First of all, there are tangible and intangible legacies. In the same vein, certain authors speak of hard and soft legacies, or of physical and spiritual legacies, as the Organising Committee of the Atlanta Games indicated (see above). A new conference facility built for a mega event, such as the one hosting the International Broadcast Centre in Vancouver during the 2010 Olympic Winter Games, is a tangible legacy. By hosting the 1994 Commonwealth Games in facilities that were for the most part temporary - of which no trace remains - the city of Victoria (Canada) demonstrated that these games could be held in medium-sized cities, which thus constitutes an intangible legacy for the Commonwealth Games Federation (CGF). The 2012 Olympic Park is a tangible legacy which will transform the heart of East of London (LAP commitment 2) but also an intangible legacy as it should be a blueprint for sustainable living (LAP commitment 5)

We can then make a distinction between territorial and personal legacies. There are legacies that are attached to the territory that has organised the mega event and others that belong to those who have experienced it but can easily leave the said territory. The competencies acquired by the individuals who have worked on the event are personal and so are the legacies outlined in the third commitment of the London 2012 LAP (see above). A better notoriety for the city hosting the event, acquired for the occasion, is territorial because clearly attached to the city. Manchester rose from 19th to 13th position in the European Cities Monitor after having organised the 2002 Commonwealth Games, which constitutes a legacy that is both territorial and intangible.

Naturally, there are also legacies that are directly related to sport, such as a facility built specifically for the mega event or on the contrary that are completely unrelated to sport, such as a highway to improve transport in the city. The 1998 Commonwealth Games in Kuala Lumpur left first-class sport facilities, which are clearly a sport-related legacy for the city. Surprisingly many mega sporting events Papeles de Europa 
have little (intangible) legacy in terms of sport participation (SPEAR 2009). London 2012 wants to change this and make the UK "a world-class sporting nation", both at elite and grassroots levels (LAP commitment 1).

It is possible to interlink the three dimensions presented above in order to obtain a legacies matrix for a mega sporting event. Figure 1 illustrates this matrix with examples of types of legacy.

Figure 1 - Legacies matrix for mega sporting events

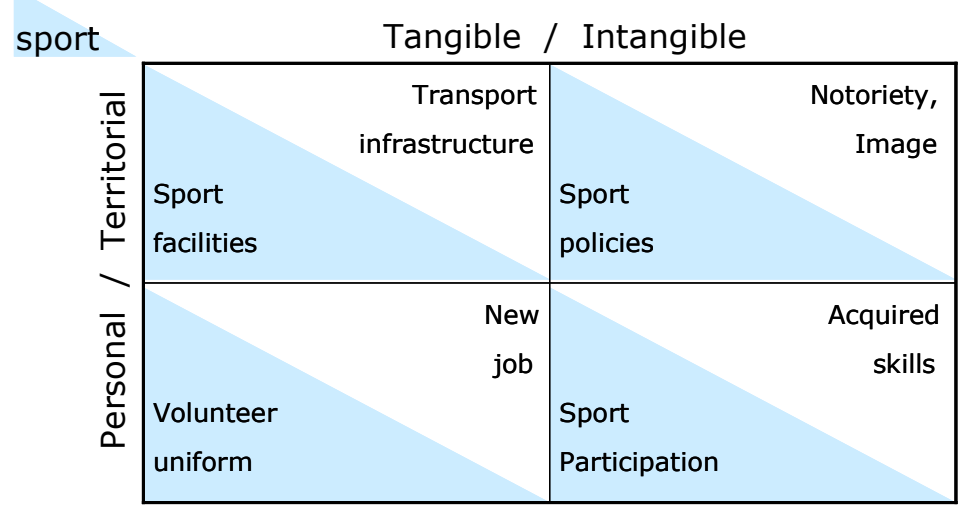

Figure 2 illustrates this matrix with some of the legacies of the Innsbruck 1964 and 1976 Olympic Winter Games based on Chappelet and Junod (2006), legacies which were reinforced with the organisation of the first Winter Youth Olympic Games in 2012.

Figure 2 - Legacies of Innsbruck 1964 and 1976 Olympic Winter Games

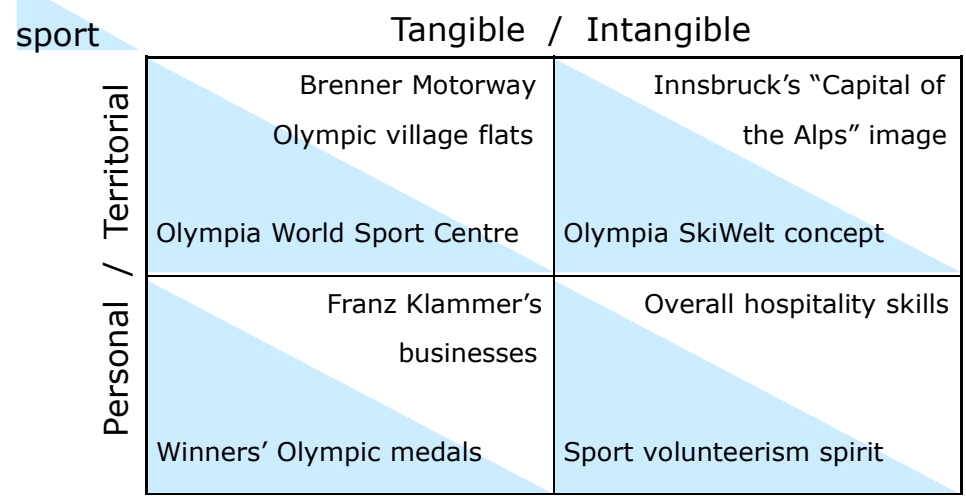

\section{MAY BE CONSIDERED}

The second element of our working definition raises the questions of temporality and perspective, the "when" and "who" of legacy. At what point in time may we consider that we are in the presence of a legacy? The inherent meaning of the concept would seem to indicate that this would take place after the event. But how many months, or years, afterwards are required to consider that we may talk of legacy? It appears necessary to make a distinction between short- or medium-term legacy (for example one or two years after the mega event) and long-term legacy (one or two decades after the event). The extremely long term should also be considered when speaking 
Chappelet, Jean-Loup. Mega sporting event legacies: a multifaceted concept.

of urban legacy, such as that which transformed the entire Barcelona sea front on the occasion of the 1992 Games, or when certain cities wished to organise a centenary of past editions (Athens 1896, Paris 1924, Amsterdam 1928). The idea is to achieve a "lasting legacy" (Delhi 2010 Commonwealth Games), yet a legacy is arguably never something that is achieved to a definitive degree, especially the intangible legacies which time can dilute.

The notion of legacy that develops "before and during" is being increasingly used, i.e. the possibility of reaping benefits from the mega event during its preparation and even during its candidature phase. As soon as it was awarded the Games, the city of Vancouver and the Organising Committee for the 2010 Winter Games created an entity named "Legacies Now!" which was responsible for ensuring that during the six years of preparations, the population would already benefit from the positive impact. The idea was adopted by the British Government who entitled its Legacy Action Plan: Before, During and After: Making the Most of the London 2012 Games (DCMS 2008).

Certain cities now plan their candidature for mega events with a view to obtaining some legacy from it even if they fail to be chosen. Specialised consultants call this strategy "Win even if you lose". The IOC has recently used this theme to encourage Olympic candidatures which are not as numerous as in the 1990s based on the cases of Chicago, Lille, Manchester and Sion (IOC 2011a). For example, despite failing to obtain the 2006 Winter Games, the city of Sion, in Switzerland, constituted a foundation to perpetuate the main theme of its candidature: sustainable development for the mountain regions. Over twelve years after the decision in favour of Turin, the foundation is still very active and may be considered as a legacy of this failing bid.

The question of perspective and point of view should also be raised. Who is in a position to consider that a particular consequence of a mega event is a legacy? Here, it would seem essential to distinguish at least three points of view on the part of three stakeholders: that of the local population, that of the urban regime i.e. the political and economic leaders of the host region (including the organising committee), and that of the owner of the event (who attributed it to the city). These points of view are subjective and do not necessarily coincide as the following examples will show.

The taxpayers of Quebec paid off the huge deficit from the 1976 Montreal Games over thirty years. As soon as the said deficit was known, the IOC saw the number of candidatures to host the Games dwindle, to the point that only a single city (Los Angeles) was prepared to organise the 1984 Games. From the point of view of the people of Montreal and the IOC members, the financial legacy of the Montreal Games is thus rather negative. From the point of view of the local political and economic elite, it is more positive since it made it possible to regenerate the eastern part of the city, and to create more balance with respect to the Anglophone part of the city in the West.

The 1984 Los Angeles Games in Los Angeles left only a limited tangible legacy behind in southern California, since virtually no facilities were built specifically for them. They did, however, provide new impetus for Olympic candidatures - something essential for the survival of the IOC - thanks to the considerable financial profit achieved from the Games. From the point of view of an owner of a mega event - 
Chappelet, Jean-Loup. Mega sporting event legacies: a multifaceted concept.

such as the IOC or the CGF - an overall positive legacy is a crucial argument to quell local criticism and above all to ensure that other cities will submit candidatures in the future. The Organising Committee, which is dissolved after the Games, also strives to ensure that its legacy is recognised: for example by ensuring that a dedicated web site is maintained (see the site presenting the legacy from the 2002 Commonwealth Games in Manchester: www.gameslegacy.co.uk) or that an entity perpetuates the memory of the mega event (such as the foundation created in Los Angeles with the benefits of the 1984 Games: www.la84foundation.org).

It is generally accepted by the local stakeholders as well as by the IOC that the 1964 and 1976 Olympic Winter Games organised in Innsbruck (Tyrol, Austria) left a great tangible legacy in the form of sport facilities which were maintained and developed after both Games to host many sporting events (Chappelet and Junod 2006). The Organising Committee of the first Winter Youth Olympic Games held in Innsbruck in 2012 used these sport facilities and did not have to build new ones. Hence it cannot boast of some tangible sport legacy. However, it was keen to emphasise in a local advertising campaign that these Games were "Good for Tyrol" and "Good for Youth", slogans aimed at both the urban regime and the local population. The first Winter Youth Games also proved "good for the IOC" as they demonstrated that it was possible to organise such an event at rather low cost (compared to the first Summer Youth Games edition in Singapore which had seen its budget skyrocket).

\section{CONSEQUENCES OF THE EVENT}

The word "consequences" is intentionally a neutral one. A legacy may, in fact, be either positive or negative depending on the point of view or on (subjective) personal opinion. According to its Charter (IOC 2011b), the IOC wishes to favour a "positive legacy" (Rule 1.14). Certain facilities relating to mega events have nevertheless become somewhat cumbersome legacies (the so-called "white elephants") that are expensive to maintain: examples here are most bobsleigh runs for the Winter Games or the artificial white water canoeing parks for the Summer Games. Most of the sports facilities for the 1968 Winter Games in Grenoble, France, were demolished after the Games rather than assuming their maintenance costs. Several stadiums built on the former Athens airport for the 2004 Games have been abandoned. Some host cities have founded ad hoc organisations and, thanks to the operating profits from the Games, have created legacy funds to ensure that the sports venues built for the Games can continue to be used. This was the case after the Winter Olympics in Calgary (Canada), Salt Lake City (USA) and Turin (Italy).

The notion of "consequences" also raises the question of causality: what is really caused by a mega event, and what is not? We also encounter this question in relation to impact studies. Should the Syntagma-Glyfada tramway and the new Athens airport be seen as legacies from the 2004 Olympic Games in the Greek capital? Or should the Royal Commonwealth Pool and the Meadowbank Stadium in Edinburgh be seen as legacies from the 1986 Commonwealth Games in the Scottish capital? The construction of these general infrastructures or sports facilities is often simply a case of planned work being carried out earlier because of the mega event, although it would have taken place in any case at a later date. 
Chappelet, Jean-Loup. Mega sporting event legacies: a multifaceted concept.

But where do you stop? With hindsight, should the massive public deficits on the part of Greece which appeared in 2009 or the popular decision for Scotland's devolution in 1997 be attributed to the aforementioned Games? The mega sporting events do catalyse a great deal of energy and projects, but cannot be held responsible for everything that takes place in a city, nor can they be seen as a cure to all ills. It is often difficult to distinguish between the mega event legacy and the regular municipal governance legacy.

Finally, it is impossible to plan everything. The organisers of mega events nowadays plan to leave a positive legacy, but it is essential to realise that certain legacies occur without being planned, i.e. those considered to be negative (see above) but also some that are positive. For example, tourism decreased in Athens during the two years prior to the Games: possibly as a result of reports by the international press evoking delays with construction sites throughout the city. Instead, tourism increased in Beijing before and after the 2008 Olympic Games without the organising committee or the Chinese tourism state agencies planning for it.

As we have seen, the Legacy Action Plan drawn up by the Department of Culture, Media and Sport (DCMS) after the 2012 Games were attributed to London outlines "five legacy promises" that have been the subject of public policies by the Labour Governments of Tony Blair and Gordon Brown. The coalition Government of David Cameron has cut in many of the policies aimed at furthering youth participation (LAP commitment 1), hence wasting an opportunity that could have turned into a positive legacy but will now most probably be remembered as a negative legacy of the 2012 Games because participation in some Olympic sport did decreased in the UK during the Games preparation years (Keech 2012). The same coalition government decided one year before the Games to double the budget for the Olympics security and the opening and closing ceremonies clearly aiming at fulfilling the fifth and last LAP commitment (the UK as a creative, inclusive and welcoming place). It is after the Games that it will be possible to run opinion polls to see whether this planned legacy has been achieved.

As shown by Chappelet (2008), the organisation of the Olympic Winter Games since the 1970s has raised many issues concerning the protection of the local environment. Since the 1990s some winter Olympic cities and bids have based their project on the idea of sustainable development. The current and universal concerns for these ideas in mega sport events can be seen as an unplanned legacy of the Olympic winter games.

Naturally, organisers focus on the planned positive legacies using a "top down" approach. We could call the unplanned legacies "bottom up" ones. The governance structures of the host city, region and country can considerably facilitate - or hamper - the creation of these two sources of positive (or negative) legacies.

\section{IN ITS ENVIRONMENT}

The legacy of a mega event can have an extremely variable territorial extent: it can affect its local, regional, national or global environment. There are numerous examples on the local or even micro-local level if we consider the districts built on the 
Chappelet, Jean-Loup. Mega sporting event legacies: a multifaceted concept.

sites of athletes' villages created for the Olympic or Commonwealth Games. Once again, these legacies can be either positive or negative. The village for the Grenoble Games has today become a ghetto, whereas that built for the Sydney Games has become an exemplary eco-friendly settlement.

On a regional level, the volunteers at the 1992 Albertville Winter Games formed an association with a view to promoting tourism in the Savoie region. Ten years after the Games, they were still using the silver uniforms with the Olympic logo which were both their personal, tangible legacy and the symbol of an extremely strong, intangible regional legacy. As explained above, the first Winter Youth Games organisers were keen to show the value for the region of Tyrol to host these Games. The Commonwealth Games are often the opportunity for a second-tier region to show its strengths. This will certainly be the case with the 2014 Games in Glasgow, Scotland, a nation that some of its politicians would like to see independent. The autonomous region of Catalonia largely benefited from the regional legacy of the Barcelona 1992 Games.

The Beijing Games in 2008 were seen by millions in China as a national legacy to the Chinese people who was able to show its long-forgotten pride (Close et al. 2007). From the point of view of the Chinese government and many external observers, the 2008 Games also marked China's accession to becoming a major power (Price and Dayan 2008). This legacy unique to China, mentioned by the IOC's Evaluation Commission for the 2008 candidatures (see above), can be considered a global one.

Through its International Inspiration programme the London Olympic Organising Committee (LOCOG) has tried to expend the legacy of the 2012 Games beyond the borders of the UK to the globe. This global legacy programme aims to deliver on the Games' bid promise to reach young people all over the world and connect them to the inspirational power of the Games, so they are inspired to do sport. Over 12 million young people have been reached according to LOCOG (2012).

\section{CONCLUSION}

As we have seen, the notion of legacy is multi-faceted and far-reaching. We could even say that even the fact that discussion on this topic is continuing - which was the purpose of this article - is a form of legacy from the organisation of all the mega events since the 1990s, when the concept started to be researched, and even though examples of such events organised well before then can also be mentioned in this discussion. The concept legacy can be stretched a lot and the debate on mega sport event legacies is never ending.

In fact, debate on legacy has to a large extent replaced debate on mega event impacts, especially as positive economic impacts are more and more contested by experts (for instance Andreff in this issue and several other publications, Barget and Gouguet 2007, etc.). Sociocultural and environmental impacts should also be considered in addition to economic impacts as suggested by the IOC with its Olympic Games Impact (OGI) framework which defines 160 indicators to measure the impact of an edition of the Olympics in the three spheres of sustainable development (economic, social and environmental) over a ten-year period (IOC 2009).

Papeles de Europa

25 (2012): 76-86

Doi: http://dx.doi.org/10.5209/rev_PADE.2012.n25.41096 
In particular, social legacies are more and more important because communities which host mega sporting events are searching for a greater sense of belonging and well-being, as well as for the "feel good factor" that researchers have identified as an intangible factor resulting from a well organised event. Some say that the rationale for awarding the 2012 Olympics to London rather than Paris was the social legacies that were promised in terms of sport participation by the young people in Britain and beyond. We have seen that these legacies are hard to secure. In that sense, legacy can be seen as a bridge between the dreams created by the mega event organisers and the realities of territorial development experienced by elected officials.

We should note, however, that everything we have just said applies essentially to one-off mega events in a given city unlike recurring ones that take place each year in the same city. Recurring events have less need of the concept of legacy. The fact that they continue to be organised means that they are considered to be valid by their stakeholders and bring legacies to their cities. Those that benefit from a longstanding tradition, such as the Wimbledon tennis tournament or the Boston Marathon are veritable gems within the intangible legacy of the cities concerned (which should perhaps apply to join the UNESCO World Cultural Heritage list).

Certain cities have systematic policies of hosting both one-off events from one year to another but also regular ones throughout the year. This is the case of Lausanne (Switzerland), the Olympic capital. It is also that of Melbourne (Australia), which hosted the 1956 Olympic Games and the Commonwealth Games exactly fifty years later, and between the two organised many world championships, the 2002 World Masters Games and - each year - is the venue for the Australian Tennis Open, Formula 1 Grand Prix races, the Cricket Boxing Day Test Match, etc. It is interesting to note that the term "legacy" appears for the first time in the official report of the Melbourne 1956 Games.

Such a public policy of regularly hosting sporting events exists in other cities which have hosted the Olympic and/or Commonwealth Games such as Edmonton and Manchester (Misener and Masson 2009) but have realised that these one-off events cannot bring alone long lasting benefits. A public hosting policy is an effective mean to foster a sustainable legacy that continues beyond a single event, however large, and that is created progressively on the basis of the successes and failures of each recurring event organised in a given city and that, overall, should constitute a unique heritage for this city and for sport. 
Chappelet, Jean-Loup. Mega sporting event legacies: a multifaceted concept.

\section{REFERENCES}

ABC (1997). A Legacy for Olympism. Athens: 2004 Olympic Bid Committee.

ACOG (1997). The Official Report of the Centennial Olympic Games. Atlanta Committee for the Olympic Games: Peachtree Publishers, 23. Available at: www.la84foundation.org/6oic/OfficialReports/1996/1996v1.pdf (accessed 16th July 2012).

Barget, E. and Gouguet, J.-J. (2007). "The total Economic Value of Sporting Events: Theory and Practice", Journal of Sports Economics, 8, 165-182.

Cashman, R. (2003). "What is Olympic Legacy" in The Legacy of the Olympic Games, 1984-2002 (Miguel de Moragas, Christopher Kennett and Nuria Puig, Eds.). Lausanne: International Olympic Committee, 31-42.

Chappelet, J.-L. (2003). "The Legacy of the Winter Games: An Overview" in The Legacy of the Olympic Games, 1984-2002 (Miguel de Moragas, Christopher Kennett and Nuria Puig, Eds.). Lausanne: International Olympic Committee, 5466.

Chappelet, J.-L. and Junod, T. (2006). "A Tale of 3 Olympic Cities: What can Turin learn from the

Olympic legacy of other Alpine cities?" in Major Sport Events as Opportunity for Development,

Proceedings of the Valencia Summit 2006 (D. Torres, Editor), Valencia: Instituto Nóos, 83-89.

Chappelet, J.-L. (2008). "Olympic Environmental Concerns as a Legacy of the Winter Games", The International Journal of the History of Sport, 25 (14), 1884-1902.

Close, P. Askew, D. and Xu, X. (2007). The Beijing Olympiad: The Political Economy of a Sporting Mega-Event. London: Routledge.

DCMS (2008). Before, During and After: Making the Most of the London 2012 Games. London: Department of Culture, Media and Sport.

Gratton, C., and Preuss, H. (2008). "Maximizing Olympic Impacts by Building up Legacies". The International Journal of the History of Sport, 25(14), 1922-1938.

Hiller, H. (2003). "Towards a Science of Olympic Outcomes: The Urban Legacy" in The Legacy of the Olympic Games, 1984-2002 (Miguel de Moragas, Christopher Kennett and Nuria Puig, Eds.). Lausanne: International Olympic Committee, 102-109.

IOC (2001). Evaluation Commission Report, Games of the XIX Olympiad in 2008. Lausanne: International Olympic Committee.

IOC (2009). 2018 Candidature Acceptance Procedure. Lausanne: International Olympic Committee.

IOC (2011a). Beyond the Bid, Thriving Today: Legacies of Bidding for the Olympic Games. Lausanne: International Olympic Committee.

IOC (2011b). Olympic Charter: In Force as from $1^{\text {st }}$ July 2011. Lausanne: International Olympic

Committee, page 13.

Keech, M. (2012). "Youth Sport and London's 2012 Olympic Legacy" in Watching the Olympics, Politics, Power and Representation by John Sugden and Alan Tomlinson (Eds.). London: Routledge, 82-96.

LOCOG (2012). International Inspiration. London Organising Committee for the

Olympic Games. Available at: www.london2012.com/join-

Papeles de Europa

25 (2012): 76-86

Doi: http://dx.doi.org/10.5209/rev_PADE.2012.n25.41096 
Chappelet, Jean-Loup. Mega sporting event legacies: a multifaceted concept.

in/education/international-inspiration (Accessed 15th July 2012).

Misener, L. and Masson, D. S. (2009). "Urban Regimes and the Sporting Events Agenda: A Cross-National Comparison of Civic Development Strategies", Journal of Sport Management, 22(5), 603-627.

NAOOC (1999). Official Report of the $19^{\text {th }}$ Olympic Winter Games. Nagano Olympic Organising Committee.

Price, M. E. and Dayan, D. (Eds.) (2008). Owning the Olympics, Narratives of the new China. Ann Arbor: The University of Michigan Press.

SPEAR (2009). A Systematic Review of Evidence Base for Developing a Physical Activity and Health Legacy from the London 2012 Olympic and Paralympic Games. London: Centre for Sport, Physical Education and Activity Research, Department of Health. 